\title{
Rompiendo tabúes sexuales en la literatura rumana contemporánea: el caso de Adrian Schiop en Zero grade Kelvin
}

\author{
Diego MuÑoz CARRobles \\ Universidad Complutense de Madrid \\ munozcarrobles@gmail.com
}

\begin{abstract}
RESUMEN
Este artículo pretende dar a conocer algunas de las claves interpretativas de la novela Zero grade Kelvin, escrita por el novelista rumano Adrian Schiop, mediante la cual introdujo el tema de la homosexualidad en el mercado editorial de su país de una forma descarnada y sin censura. El erotismo representado en la novela carece de elementos positivos, las relaciones sexuales del solitario protagonista masculino están marcadas por la búsqueda constante y la insatisfacción.
\end{abstract}

Palabras clave: Adrian Schiop, literatura rumana, erotismo, deseo sexual, pedofilia.

\section{Breaking Sexual Taboos in Contemporary Romanian Literature: Adrian Schiop's Zero Grade Kelvin}

\begin{abstract}
This paper tries to analyse some of the interpretational keys of Zero grade Kelvin, a novel written by Romanian young novelist Adrian Schiop, thanks to which the topic of homosexuality was introduced in the Romanian literary market in an uncensored and brutal way. The eroticism represented by Schiop in the book lacks of positive elements, the sexual relationships of the lonely main male character are marked by a constant search of lovers and dissatisfaction.
\end{abstract}

Keywords: Adrian Schiop, Romanian literature, eroticism, sexual desire, paedophilia.

\section{Introducción}

La novela que nos ocupa, Zero grade Kelvin, aparece en Rumanía en 2009, publicada en la colección EGO, de la editorial Polirom, serie que da cabida a jóve- 
nes literatos rumanos, a valores «en alza» de este panorama literario. Adrian Schiop (n. 1973) ya había sorprendido a la crítica con su debut Pe bune/pe invers (2004) y ahora, en este segundo trabajo, vuelve a tratar temas como la soledad de un hombre joven, la aceptación de la propia homosexualidad o las relaciones sexuales furtivas.

¿Cómo explicar, en pocas palabras, en qué consiste este libro? Básicamente narra la historia de un emigrante rumano en Nueva Zelanda, su desarraigo, sus compañeros de fatigas con quienes realiza trabajos en la construcción o la recogida de fruta, sus intentos frustrados de conocer a otros hombres y, por fin, su gran deseo oculto, la pulsión sexual que siente hacia niños y adolecentes. Es de comprender, pues, que con esta temática la novela causara «cierto revuelo» entre la crítica literaria rumana, no demasiado acostumbrada a ver aparecer estos temas (homosexualidad, pedofilia) en las obras publicadas últimamente por las grandes editoriales. No obstante, llama la atención que la novela fuera «lectura recomendada» por la revista Maxim, publicación de gran difusión orientada al público masculino.

Hasta qué punto la historia que configura esta novela se encuentra inspirada en la experiencia personal real del autor, Adrian Schiop, que pasó unos años en Nueva Zelanda ejerciendo las más variopintas profesiones para ganarse la vida, resulta difícil de discernir. En cualquier caso, Zero grade Kelvin no constituye en sí misma ni un relato sobre la inmigración, ni una historia de sexo pedófilo, ni las memorias de un gay frustrado, sino más bien las experiencias de un adulto que se resiste a serlo, embarcado en una huida camuflada de viaje iniciático, pero que acabará, suponemos, en su Ítaca particular, Rumanía.

Pero no queremos olvidar el título de este trabajo e insistiremos en la idea de romper tabúes: por un lado, la novela rompe el tabú de la orientación sexual en la literatura rumana en dos aspectos, la homosexualidad y la pedofilia, temas poco frecuentes sobre todo en las grandes editoriales -Polirom, en este caso-; por otro lado, se rompe con el tabú del lenguaje cuidado, ya que Adrian Schiop utiliza un registro vulgar, plagado de expresiones que chirrían todavía en los oídos de gran parte de los lectores rumanos; y por último, se acaba con una cierta idealización de la «diáspora» rumana en el exterior, que en esta obra será retratada de manera feroz, totalmente carente de solidaridad, de perspectivas de futuro o proyectos de estabilidad y volcada hacia el sexo y la marginación.

\section{Erotismo y sexualidad en Zero grade Kelvin}

Ahora bien, ¿cómo es el erotismo en este volumen? A pesar de que la novela no pertenece al género erótico, el registro erótico, las alusiones al sexo y el deseo sexual son ingredientes clave para entenderla. El deseo de «follar» (a fute, en rumano) está omnipresente en las páginas del libro; de hecho, la pulsión sexual mueve a los personajes de la novela, y no solo al protagonista, sino también a los personajes secundarios. Los personajes de Zero grade Kelvin constituyen más bien un conjunto de «outsiders», de personas que actúan, trabajan y viven fuera del sistema, son inmigrantes en Nueva Zelanda y no llegan o no pueden mezclarse con la población local más que en raras ocasiones. Su vida se mueve en el presente, no poseen espe- 
ranzas más que la obtención esporádica de placer sexual como remedio contra la soledad del inmigrante.

En general podemos decir que la representación del sexo es bastante cruda, sin tapujos, lo cual se hace patente en el uso del lenguaje, especialmente vulgar y sin eufemismos, todavía chocante para el lector rumano contemporáneo. Tenemos, eso sí, varios grados, que fluctúan entre la fantasía y la consumación del acto sexual: hay fantasías sexuales con adolescentes idealizados, relatos de experiencias sexuales de la infancia y la adolescencia -igualmente idealizadas o exageradas- y, por último, descripciones de relaciones sexuales esporádicas homosexuales y heterosexuales.

Insistimos en el hecho de que, pese a no ser Zero grade Kelvin una novela erótica, la constante «amenaza» del deseo sexual la convierte en material adecuado para un análisis desde el punto de vista erótico y sexual. En palabras de la crítica rumana, «sobre todos los personajes planea la sombra de la soledad» pero ante todo encontramos «mucho sexo de todo tipo». De hecho, «no hay una página en la que no se hable de sexo» y ésta sería, en opinión de algunos críticos, «la clave del mundo absolutamente trágico» que se recrea en esta novela:

Asupra tuturor planează umbra singurătătii ca adevăr ultim al existenţei, ignorat şi combătut, însă, cu toate armele cunoscute: prieteni, familie, sex, foarte mult sex de toate felurile. Nu există pagină în care să nu se vorbească despre sex şi aici este şi cheia lumii absolut tragice pe care romanul o construieşte: nimeni nu face sex, toţi nu fac decât să spună povești cât mai pervers-lugubre despre asta. În realitate, corpurile par să nu se mai poată lipi unele de altele nici măcar pentru o acuplare oarecare, darmite pentru iubire, asa că poveştile sexuale devin un fel de folclor salvator de care aceste păpuşi dezarticulate se agaţă cu inconştientă disperare. (Mihalache 2009)

\section{Los grandes temas de la novela}

\subsection{La homosexualidad}

Lejos de ser una reivindicación de la homosexualidad como una forma de orientación sexual más, ésta sirve de marco para comprender la psicología del protagonista, el cual define en pocas palabras su pasado y sus preferencias sexuales en uno de los fragmentos clave del relato:

Y es que no puedes hacer otra cosa más que pensar en eso, en qué guay tiene que ser tener a dos chavales solo tuyos, solo para ti, sí, qué bien, pensaba, tan bien que de repente se me empinó, así, e inmediatamente después, sentí que quería ser su papaíto, el de aquellos chavales y desde entonces cada vez que veía una panda de chavales guapos, quería solamente ser su padre... Tuve relaciones más largas, a los diecisiete, con un chico tímido de siete años, Raducu, que había ido a pasar las vacaciones con sus abuelos, y, a los diecinueve, con dos hermanos de diez y once años respectivamente; de cualquier modo ninguno de ellos nunca supo que eran mis amantes. Al primero, a Răducu, le agarré del miembro y le provoqué varias erecciones, a los otros dos, cuando yo tenía diecinueve, les enseñé mi pene erecto, animándoles a que 
me lo tocaran -lo cual ellos hicieron-, y más o menos esta fue toda mi vida sexual hasta los veintiséis años, cuando por fin conseguí hacerme homosexual. (Schiop 2009: 53) ${ }^{1}$

Aquí veríamos por un lado su manera de entender las relaciones sexuales como un reparto desigual de fuerzas, durante el cual él resulta ser el «padre» (taticul, su 'papito', escribe el autor), es decir, el que ostenta el poder, mientras que sus partenaires ni siquiera comprenden estar inmersos en un acto sexual («de cualquier modo ninguno de ellos nunca supo que eran mis amantes»), es decir, el protagonista defiende el modelo de relación sexual en el cual la orientación sexual de los actores queda al margen, mientras que lo verdaderamente importante es su carácter pedófilo, ya que aprovecha la ignorancia y la inmadurez de sus «amantes», cualidades que refuerzan su posición dominante en el acto sexual.

Nos sorprende igualmente cómo resume en una línea la cuestión referida a la propia identidad sexual: "por fin conseguí hacerme homosexual», declara sencillamente el protagonista. Pero, ¿qué significa para él ese «conseguí»-am reusit, en rumano, lo he logrado-? Supone, como ya veremos más adelante, una mayor aunque no total aceptación de sí mismo y de su orientación sexual, así como un progresivo abandono de la obsesión por los niños.

La madurez «sexual» del narrador/protagonista se va configurando poco a poco, si bien se sentirá atraído en todo momento por personajes claramente infantilizados o que, al menos en su percepción, están más cerca de la infancia que de la edad adulta. Tal es el caso de Hiroaki, un joven japonés que conoce en el albergue donde se encuentra alojado durante los primeros meses de su estancia neozelandesa y con quien fantasea continuamente en la primera parte de la novela. «Mi mirada le acaricia la cara discretamente, Hiroaki es hermoso y me he acostumbrado a que me guste, y he aquí que le saludo y él asiente con la cabeza, mientras sonríe ambiguo» (Schiop 2009: 37). Se establece una relación distante pero que despierta la ternura del protagonista, aunque tememos que esta ternura esconde en el fondo un poco de ese falso deseo paternal del que hablábamos anteriormente. «Los japoneses son los más interesantes», dice en otro momento el protagonista, «me fascinan: no tienen vello en la cara, y además no puedes leer nada en sus ojos opacos, la contracción de sus pupilas se ahoga en el negro mate de sus iris, no sé, no me inspira ni miedo ni desazón» (Schiop 2009: 48).

La manera tan positiva en que describe a los japoneses nos lleva a pensar que ve en ellos a unos niños grandes, cuya inocencia se demuestra a través de sus caras imberbes y sus miradas inocentes. En el caso de Hiroaki, la atracción es correspondida, pero de nuevo el narrador no llega a pasar a la acción: “'Pero si tú no tienes opinión ni nada, todo te parece bien, dime algo que te guste de veras'. 'Tú' -me respondió y esto me puso en un aprieto» (Schiop 2009: 52).

El protagonista realiza, junto a sus compañeros Lorand y Nicu Popa, numerosas incursiones en el mundo de la noche, especialmente en la discoteca Voodoo, lugar

\footnotetext{
1 Todas las traducciones de la novela de Schiop son del autor del artículo.
} 
de encuentro para jóvenes homosexuales. En ese espacio tienen lugar verdaderas escenas de «caza», cuyo objetivo único es calmar el deseo sexual y encontrar un amante que no haga demasiadas preguntas.

Se me acercó un italiano de unos cuarenta años, al que había conocido la última vez, y que me había puesto la cabeza loca contándome las vacaciones que había pasado en todo tipo de destinos selváticos y con chavales exóticos que conocía en locales exclusivos de allí. «Naughty boy, naughty boy» repetía después de emborracharse, mientras jugaba con la cremallera de mi cazadora. (Schiop 2009: 78)

Las relaciones personales que se establecen en este tipo de locales son, por lo tanto, efímeras, apresuradas, insatisfactorias. A lo largo de la novela veremos la predilección del protagonista por los maoríes, y no tanto por el resto de la población neozelandesa. Se siente atraído por los rasgos indígenas de este pueblo, quizás en un intento de buscar un compañero sexual que no se parezca a él, que se sitúe en un plano físico y mental diferente al suyo.

Me dirigí hacia la puerta y allí vi a un tipo regordete, bajito y con pinta de polinesio -tenía la piel de color café y fina, la nariz aplastada y las fosas nasales anchas. Sí, me podría llegar a gustar, era el momento de hacer algo [...]. «¿Te molesta si te toco?», le pregunté, él me dijo que no con la cabeza y entonces lo tiré hacia mí y tuve una especie de escalofrío cuando lo besé, luego él empezó a buscar mi labios y esto me gustó menos, pero la cosa iba bien, por fin él me pidió que fuéramos a otra parte, dónde, pregunté, por aquí, me respondió él a la vez que me indicaba una dirección con la mano -y yo me fui detrás de él, que me llevaba a los baños. (Schiop 2009: 80)

Con este personaje inicia nuestro protagonista una breve «relación» basada casi exclusivamente en el sexo: «una vez llegaba a casa, lo único que hacía era tirar de mí y meternos en la cama y yo tenía que follármelo y a mí no me gustaba follármelo, y no sabía y a veces ni se me empalmaba, me entraba el pánico y me bloqueaba» (Schiop 2009: 84). En el fondo, el personaje narrador y protagonista de la novela siente un vacío interior con este tipo de relación, necesita algo más profundo, con sentimientos, aunque no lo sabe expresar bien cuando intenta acabar con esta aventura:

Tenía pues que permanecer duro y frío como el diamante hasta el final, así que le dije que la culpa era del «a la cama, a la cama», que yo necesitaba hablar con alguien y él solo «a la cama, a la cama», asentía dócil con la cabeza, sin responder, «yo necesitaba que me comprendieran y me apoyaran y tú, fóllame, fóllame», él era increíblemente dócil, se había perdido como un niño pequeño. (Schiop 2009: 87)

Nuevamente, en la segunda parte de la novela aparecerá un personaje secundario casi idéntico, «un chaval maorí de dieciocho o veinte años», «un autista radical, sin compromisos» (Schiop 2009: 164). Así pues vemos cómo bajo el deseo sexual subyace otra capa más profunda de necesidad de amar y ser amado, si bien ésta sólo aflora en determinados momentos y permanece el resto del tiempo sometida a la pulsión sexual. «Mi madre me había dado dinero para que me estableciera aquí, con la 
esperanza de que en NZ me ganara la vida, encontrara un tío con quien vivir -y ya que esto no había sido posible en Rumanía, ¿por qué aquí sí?» (Schiop 2009: 170).

Finalmente queremos insistir en el carácter «periférico» que el autor otorga a la homosexualidad, es decir, es un rasgo que se añade a la condición de marginado, de «outsider» del personaje protagonista, que es homosexual porque no es lo común y si en algún momento esa orientación sexual sirve para crear algún vínculo emocional o formal, entonces habrá que desestimarla. Tal y como dice la crítica sobre Adrian Schiop, la causa de la emigración es la esperanza de «un mundo sexual mejor»:

$\mathrm{Nu}$ complexul de «lumea a treia» este însă cel care devine argument suprem în decizia personajului de a-l urma pe Nicu Popa în NZ, ci speranţa legată de o lume sexuală mai bună. $\mathrm{Cu}$ un profil de pedofil complet lipsit de experienţă, care pretinde că se străduieşte să «evolueze» într-un homosexual, personajul este suficient de naiv să creadă că în Occident «sexualitatea tradiţională e scoasă discret pe margine, în timp ce sexualităţi ca la gay sînt promovate în centru», ajungînd însă, în cele din urmă, să accepte că haosul şi deruta care domniseră în primii ani ai României postrevoluţionăre constituisera un mediu mult mai generos pentru anumite devieri. (Ispas 2010)

De hecho, el propio autor defiende que el modelo de orientación sexual gay que tiende a parecerse al modelo tradicional de familia heterosexual no le interesa, y por ello buscaba añadirle complejidad al personaje principal a través de experiencias sexuales que, como veremos más adelante, distan de ser perfectas o satisfactorias:

Credeam că oamenii, relational, ar avea de câştigat dacă ar renunţa la formula binară a cuplului şi a familiei (hetero sau gay, nu fac distincţie fiindcă căsătoria gay e o formă de a perpetua modelul ăsta istoric) şi că, dacă atât gay-i cât şi hetero, ar încerca sa se bisexualizeze, lumea ar deveni mai bună sau măcar mai interesantă. In subtext, era şi ideea că homosexualitatea exclusivă, aşa cum e ea normată în societatea occidentală, şi-a epuizat potenţialul subversiv şi că de fapt la ora actuală ar conserva status quo-ul; că singura bisexualitatea neagă formula asta binară a cuplului, pe care se sprijină familia - întrucât, dacă îti plac şi tipii si tipele, atunci, dpdv al identităţii afective, nu te poate satisface modelul unui singur partener, prin forţa lucrurilor închis într un singur sex. E simplu de probat că nu homosexualitatea (cum argumentează Wittig si Butler), ci bisexualitatea e refulată în societatea de acum: nu există nici un om politic important care să fie bisexual - e fie gay, fie straight; de asemenea, când un om politic in the closet face coming out ca i plac tipii, renunţă la partenerul de sex opus, fiindcă dacă ar ramane acolo ar fute unitatea familiei. (Morosan 2010)

\subsection{Sexualidad y pedofilia}

Sin duda alguna, uno de los aspectos más llamativos de la novela lo compone la atracción del protagonista por los niños, su pedofilia confesa. Se trata de un trastorno psíquico y sexual que consiste en el interés erótico hacia los niños, un interés que se basa en el trato de superioridad y de desigualdad que se establece entre adulto y 
niño en la relación. Así pues, Adrian Schiop dibuja a un emigrante desarraigado, incomprendido, solitario y pedófilo, para el cual su propia inclinación sexual es un «pequeño secreto especial»:

Se trata de aquel pequeño secreto especial, que nadie, ni siquiera los baches del asfalto conocen y que, yo, egoísta de mí, me guardo sólo para ti, para que lo consumas en tus momentos más íntimos, solo bajo el edredón... Pero para entendernos: no ha sido fácil, nadie dijo que lo fuera. He sufrido, he luchado, me he pajeado mientras pensaba en chavales de trece, catorce, dieciséis y por fin dieciocho años y sobre todo le pedía a Dios y un día mis plegarias fueron escuchadas y cuando estaba en la cama junto a Dan, mi compañero de habitación en la residencia de estudiantes, me levanté de repente con una pequeña erección. Entonces lloré de alegría, me alegré y luego me entristecí: un capítulo de mi vida tocaba a su fin, tenía veinticinco años... Luego empecé a follar con tíos de dieciocho, luego de veinte, de veinticuatro, de veintiocho y por fin, de treinta; como si fuera un sueño seguí follando hasta que vine a NZ, y mantenía la esperanza de que, llegado el momento, empezaría a gustarme. (Schiop 2009: 55-56)

En este fragmento vemos la lucha interior que se establece en el protagonista. Por un lado, su «pequeño secreto» y el deseo sexual hacia los adolescentes y, por otro, la convención social de que lo normal era mantener relaciones sexuales con gente de su edad, esa es la esperanza que conserva cuando llega a Nueva Zelanda, que le guste tener sexo con adultos, que llegue un momento en que su «secreto» se desvanezca, pero veremos que la pulsión pedófila es más poderosa que su fuerza de voluntad.

«Odiaba a los que tenían vidas normales» (Schiop 2009: 179), llega a decir el protagonista con respecto a su vida anterior en Rumanía, es decir, él siente que sus gustos sexuales no entran dentro de lo que comúnmente se conoce como «normalidad». Aun así, intenta vivir con ese deseo de la manera más normal posible, incluso lo comparte con algunos de sus compatriotas: «Tú te quedas con el chico y yo con su madre, me dice Lorand con la mirada; desde hace unos días, tanto él como NP están al corriente de mis pequeños secretos especiales» (Schiop 2009: 188).

Otro episodio, en este caso narrado por Hansie, el sudafricano que comparte albergue con los rumanos, nos ilustra hasta qué punto tiene importancia en la novela la sexualidad vivida por los niños y adolescentes. Podemos resumir con las propias palabras del protagonista: «no tengo nada que hacer con alguien que esté en el mismo nivel de conciencia que yo» (Schiop 2009: 222), es decir, detesta la igualdad en las relaciones sexuales, solo le alimenta el hecho de sentirse superior, un deseo que vería cumplido a través de la pederastia o bien mediante las relaciones que mantiene con chavales maoríes, con los cuales puede ejercer un reparto de fuerzas desigual.

Sobre este aspecto de Zero grade Kelvin, la crítica rumana ha dicho que falta profundidad y sobra psicoanálisis:

Pedofilia irepresibilă a naratorului ar avea sanse de profunzime artistică, dacă autorul ar fi făcut efortul s-o lege de ceva material psiho-analitic. Spun asta mai mult pentru alţii - pe de altă parte, ştiu bine că determinismul freudian pe mine m-ar fi plictisit la 
culme. Supendată în aer, însă, într-o masă de indivizi proper straight şi proper gay, fantezia cu băieței pare un moft. Şi unul periculos, de la un punct încolo. Citeam ca pe ace, îngrijorată de soarta autorului. (Morpurgo 2010)

\subsection{La soledad y la omnipresencia del deseo sexual}

En Zero grade Kelvin ambos conceptos se hallan íntimamente relacionados. La soledad es la principal acompañante del inmigrante rumano en Nueva Zelanda, el deseo sexual es el motor que anima la vida de muchos de los personajes de la novela y los dos conforman fuerzas destructivas a lo largo de la obra, algo que apreció la crítica en el momento de aparición de la novela, tal y como mencionamos al principio.

Por ejemplo, el protagonista se describe a sí mismo, con sus propias palabras, como un «frustrado sexual» y un «desgraciado»; sería el producto de la soledad y la no-aceptación de sí mismo, resultado de la mezcla entre el desarraigo del inmigrante y la frustración sexual. Una vez más veremos cómo intenta autoconvencerse de que la única manera posible de aceptarse es renunciar a su deseo sexual, hacerlo a la fuerza, obligarse a mantener relaciones sexuales incluso con mujeres, a fin de conseguir ignorar su infelicidad, el despecho de no haber sido amado:

Y me preocupa poco que en este conglomerado de furias y obsesiones sexuales maníacas haya que tener en cuenta el hecho de que tengo treinta años y la impresión de que hasta ahora no he hecho nada como el resto de la gente. O que soy un frustrado sexual desgraciado, desde los veinte años no he tenido entre mis brazos ningún cuerpo que me guste, o que no follé hasta que tenía veintiséis y lo que siguió a aquello mejor podría no haber sucedido. Nunca me han querido y a quien he querido luego le cogía asco y empeoraba mi clausura. ¿Y sabes por qué? Es sencillo, porque he sido un imbécil, así es, lisa y llanamente me dio por ser un imbécil. Pero ya está, me he hecho grande y quizá me apetezca follar con mujeres, así, por aburrimiento, follaré únicamente con mujeres y follaré tanto, que tendré náuseas y empezará a gustarme. (Schiop 2009: 182)

La relación que se establece entre el deseo sexual inagotable que poseen los protagonistas de la obra y el desarraigo conforma, así pues, junto con la homosexualidad y la pederastia, otra posible línea de análisis de la obra. No sólo el personaje protagonista a quien hemos dedicado parte de estas líneas, sino también los secundarios, parecen poseídos por la pulsión sexual, que en ocasiones nubla su mente y su juicio. Hansie, el sudafricano compañero de albergue y la novia de éste, Katalina, una inmigrante húngara, o bien Nicu Popa, amigo del protagonista, una figura cercana a la de un hermano mayor, todos ellos muestran su obsesión por el sexo.

Desde la infancia sueñan con una sola cosa, el sexo, que los domina. Cuando se les da rienda suelta, ya no ven otra cosa, no saben nada más, no comprenden nada más. Solo esto les proporciona un confort emocional, el penetrar y ser penetrados. Solo aman a través de los órganos genitales. (Schiop 2009: 249) 
La vida del inmigrante en Nueva Zelanda es dura. No llegan a tejerse verdaderas redes sociales entre ellos, ya que parecen estar más preocupados por el sexo que por establecerse verdaderamente en el país. Tenemos igualmente la «paradoja del inmigrante» perfectamente retratada en las páginas de la novela: «cuando pasaron algunos meses, lo que descubrió NP fue que no le gustaba esto, que casi estaba todo mejor en Rumanía» (Schiop 2009: 175). De la frustración y la inadaptación surgen el deseo sexual, el alcoholismo y las drogas como únicas respuestas posibles. A pesar de esta relación causa-efecto entre soledad y sexo, Nicu Popa, personaje secundario de la novela, achaca el estado de constante excitación sexual a la educación recibida en el país de origen: «En Rumanía los tíos están acostumbrados a follar, desde los catorce años aprenden solo una cosa, alcohol y follar y más alcohol y follar» (Schiop 2009: 145).

\subsection{El papel de la mujer}

El último punto de nuestro análisis pretende acercarnos a la visión de la mujer que nos ofrece Adrian Schiop. A pesar de ser eminentemente masculina, la novela nos presenta interesantes rasgos femeninos dignos de tener en cuenta. En general, las mujeres son personajes descritos de manera menos pormenorizada y muchos de ellos tienen una función cercana al mal, a la tentación, que desde luego nace como fruto de la relativa misoginia del protagonista. En cada parte de la novela hay un personaje femenino de relevancia: al principio es Katalina, una inmigrante húngara que comparte albergue con el protagonista y que al final decide marcharse de Nueva Zelanda con Hansie, otro de los inquilinos. En la segunda parte tenemos a Astrid, otra inmigrante rumana que se gana la vida vendiendo su cuerpo en un salón de masaje y que al final decide marcharse del complejo de caravanas en donde viven e instalarse junto a uno de sus «clientes». Por fin tenemos a Anne, la última empleadora del protagonista, una neozelandesa que dirige una explotación agrícola y que fija su atención en el narrador, con ambiguas intenciones. En los tres casos se trata de mujeres que prestan una especial atención al sexo, aunque ni Katalina ni Astrid constituyen una «amenaza» para el protagonista; no así la tercera, Anne, quien «se manifiesta directamente, sin rodeos, ella simple y llanamente me quiere follar» (Schiop 2009: 207).

Igualmente destacables son las chicas con las que éste sí mantiene relaciones sexuales, más o menos fracasadas y decisivas para su futuro. En la celebración de fin de año, el grupo de rumanos conoce a unas chicas con quienes van a pasar la noche, el colofón sexual a la fiesta resultaba inevitable, incluso para el protagonista.

Y si se te empalma, no sé yo qué relación tiene con la sexualidad... Se me empalma, le cojo la mano e intento ponérsela sobre mi polla, me gustaría que me la agarrara con la palma de la mano o algo así, pero la chica es tímida [...] y en un momento dado me pide que salgamos fuera, a la terraza, pero allí espera que me la tire y ya no me gusta. Ahora me molesta su cara fea, deforme, caníbal. Le meto un dedo en el coño, está caliente como unas vísceras, es como si penetraras la tripa de un pez podrido que flota en la superficie del agua. Y esto no me pone. (Schiop 2009: 191-192) 
La experiencia es tan desagradable que él mismo le dirá a su amigo Nicu Popa: «he enloquecido» (Schiop 2009: 192). Después de este encuentro sexual el narrador decide que ha de volver a Rumanía y acabar con la frustrada experiencia neozelandesa. Sin embargo, aún le queda pasar un tiempo recogiendo fruta a las órdenes de la ya citada Anne. Durante una reunión con el resto de la «cuadrilla», mantendrá otra relación sexual con una chica maorí - de nuevo la fijación con los y las maoríes-, esta vez la chica tampoco tiene nombre propio, no es más que una figura, casi un objeto.

Le meto la mano por debajo de la camiseta, al principio sobre los pechos, pero como esto no me dice gran cosa, bajo por lo pliegues de debajo de las costillas, la sensación me recuerda a estar con un chico. Ella sigue con la cabeza entre las manos, no se mueve hacia mí, sigue igual de pasiva cuando le cojo la cerveza de entre los pies y deslizo la mano dentro de sus bragas. (Schiop 2009: 219)

La última relación sexual de la novela, cuyo inicio acabamos de ver, sirve como despedida de las islas, de una vida que no ha podido ser, de una sexualidad furtiva, insatisfactoria, frustrada. Por mucho que lo intente disimular u obviar el narrador, para el placer sexual el género del amante cuenta, y mucho. Por eso la sensación de insatisfacción con que concluye la novela es enorme.

\section{Algunas reflexiones sobre la obra}

En definitiva, y a modo de conclusión de este trabajo, queremos volver sobre los principales elementos de análisis de la novela, así como lanzar propuestas de reflexión sobre la misma.

Tenemos un personaje protagonista, narrador de la obra, presunto alter ego del autor, que transcurre un periodo de su vida lejos de su país con la esperanza de exorcizar sus demonios personales, pero que, sin embargo, sólo consigue reavivarlos. El «pequeño secreto especial» no sólo no desaparece sino que recobra fuerza.

La novela está plagada de personajes frustrados, antihéroes, seres incapaces de mantener lazos afectivos que vayan más allá del puro sexo.

El mundo de los inmigrantes rumanos en Nueva Zelanda es retratado de manera feroz, sin contemplaciones: un submundo con drogas, prostitución, mentiras, infelicidad y, principalmente, soledad.

Adrian Schiop construye un erotismo desmoralizante, decadente, perverso. La descripción de las relaciones sexuales es directa, vulgar, casi grosera. Los personajes no aman, follan.

\section{Bibliografía}

IsPAS, Cristina (2010): «Cu o sageta spre ratare si cu cealalta spre succes». Observator cultural, núm. 514, febrero de 2010. 
Minalache, Stefania (2009): «Adrian Schiop si pulsul prozei tinere». Time Out Bucuresti, diciembre de 2009.

Morosan, Cosmina (2010): «Entrevista con Adrian Schiop». Revista Echinox, octubre de 2010.

MoRPURGO, Ioana (2010): «Totusi, unii dintre noi prefera sa traiasca printre ei...». Observator cultural, núm. 518, marzo de 2010.

Schiop, Adrian (2009): Zero grade Kelvin. Bucarest: Polirom. 